\section{RMD Open}

Rheumatic \&

Musculoskeletal Diseases

\title{
Eosinophilia predicts poor clinical outcomes in recent-onset arthritis: results from the ESPOIR cohort
}

Dewi Guellec, ${ }^{1}$ Morgane Milin, ${ }^{1}$ Divi Cornec, ${ }^{1,2}$ Gabriel J Tobon, ${ }^{3}$

Thierry Marhadour, ${ }^{1}$ Sandrine Jousse-Joulin, ${ }^{1,2}$ Gilles Chiocchia ${ }^{4}$ Olivier Vittecocq, ${ }^{5}$ Valérie Devauchelle-Pensec, ${ }^{1,2}$ Alain Saraux ${ }^{1,2}$

To cite: Guellec D, Milin M, Cornec D, et al. Eosinophilia predicts poor clinical outcomes in recent-onset arthritis: results from the ESPOIR cohort. RMD Open 2015;1:e000070. doi:10.1136/rmdopen-2015000070

- Prepublication history for this paper is available online. To view these files please visit the journal online (http://dx.doi.org/10.1136/ rmdopen-2015-000070).

Received 15 January 2015 Revised 7 March 2015 Accepted 22 March 2015
CrossMark

For numbered affiliations see end of article.

Correspondence to Dr Alain Saraux; alain.saraux@chu-brest.fr

\section{ABSTRACT}

Objectives: To determine the prevalence of eosinophilia in patients with recent-onset arthritis suggestive of rheumatoid arthritis (RA) and to describe their features and outcomes.

Methods: We performed an ancillary study of data from a French prospective multicentre cohort study monitoring clinical, laboratory and radiographic data in patients with inflammatory arthritis of 6 weeks to 6 months duration. We determined the proportion of patients with eosinophilia, defined as a count $>500 /$ $\mathrm{mm}^{3}$, at baseline and after 3 years. Features of patients with and without baseline eosinophilia were compared.

Results: Baseline eosinophilia was evidenced in 26 of $804(3.2 \%)$ patients; their mean eosinophil count was $637.7 \pm 107 / \mathrm{mm}^{3}$. Baseline eosinophilia was ascribed to atopic syndrome in 6 of $26(23.1 \%)$ patients. After 3 years, patients with eosinophilia had higher Health Assessment Questionnaire scores ( 0.9 vs 0.5 , $p=0.004)$, higher patient visual analogue scale activity score and morning stiffness intensity $(p=0.05)$, and were more often taking disease-modifying antirheumatic drugs $(p=0.02)$. Baseline eosinophilia was not associated with presence of extra-articular manifestations.

Conclusions: Eosinophilia is rare in recent-onset arthritis suggestive of RA, and is usually directly related to the rheumatic disease. Our data suggest that patients with mild eosinophilia at diagnosis could respond worse to the treatment than those without.

\section{SIGNIFICANCE AND INNOVATIONS}

- Eosinophilia is rare in recent-onset arthritis suggestive of rheumatoid arthritis, and is usually directly related to the joint disease.

- Mild eosinophilia at diagnosis of recent-onset arthritis is a marker of poor response to the treatment.

A complete blood count (CBC) is performed routinely during the initial work up for early

\section{Key messages}

What is already known about this subject?

- A few early studies in rheumatoid arthritis (RA) suggested that eosinophilia might predict greater disease severity but suffered from a number of drawbacks.

What does this study add?

- Eosinophilia is rare in recent-onset arthritis. Eosinophilia was mild and transient in most patients. Patients with mild baseline eosinophilia might respond worse to the treatment than the remainder, as they had higher patient-assessed disease activity, morning stiffness intensity, health assessment questionnaire (HAQ) scores, and disease-modifying antirheumatic drug (DMARD) use after 3 years.

How might this impact on clinical practice?

- This study allows the clinician to interpret eosiniophilia in a context of early arthritis.

inflammatory arthritis, as the results may provide valuable information on the cause of arthritis as well as on any comorbidities. An eosinophil count $\geq 500 / \mathrm{mm}^{3}$ is considered abnormal. The most common causes of peripheral-blood eosinophilia are atopic syndrome in industrialised countries and helminth infections worldwide. ${ }^{1}$ Other causes include various infections, tumours, dysimmune disorders and drugs. Idiopathic hypereosinophilic syndrome is a very uncommon cause of eosinophilia, generally characterised by sustained eosinophilia and end-organ involvement. $^{1-3}$

Peripheral-blood eosinophilia is uncommon in rheumatic diseases but may occur in dermatomyositis, rheumatoid arthritis (RA), progressive systemic sclerosis and Sjögren's syndrome. ${ }^{4-7}$ Differential diagnoses in patients with RA and eosinophilia include 
concomitant vasculitis and hypersensitivity reactions to therapeutic agents. ${ }^{8-11}$ Few studies have addressed the prevalence and significance of eosinophilia in inflammatory joint disease. A few early studies in RA suggested that eosinophilia might predict greater disease severity but suffered from a number of drawbacks such as small sample size, selection bias and use of relative values instead of absolute values to define eosinophilia. ${ }^{12-15}$ Most of the recent studies in patients with RA or a variety of rheumatic diseases found no evidence that eosinophilia was associated with disease severity or complications. However, the patients in these studies did not have recent-onset disease, and were not naive to corticosteroids or disease-modifying antirheumatic drugs (DMARDs). ${ }^{16} 17$

Thus, two important questions remain unanswered. One is whether eosinophilia in a patient with recent-onset arthritis is related to the joint disease or should prompt investigations for another cause. The other is whether eosinophilia predicts the outcome of the joint disease.

We conducted a study designed to answer these two questions. Our primary objective was to determine the prevalence of eosinophilia in patients with recent-onset arthritis, suggestive of RA or consistent with RA. Our secondary objectives were to delineate the features of patients with eosinophilia at baseline, and 3 years later, particularly their treatments, comorbidities and final diagnoses; and to determine whether baseline eosinophilia predicted subsequent disease activity, disease severity, the development of extra-articular manifestations including vasculitis and/or comorbidities.

\section{METHODS}

This study was approved by the institutional review board of the Montpellier University Hospital, the coordinating centre for this nationwide study. Before inclusion, all patients gave their written informed consent to participate in the study.

\section{Study population}

The French Society for Rheumatology established a nationwide, longitudinal, prospective cohort, the ESPOIR cohort, to enable investigations of the diagnosis, outcome markers, epidemiology, pathogenesis and medico-economics of early arthritis and RA. ${ }^{18}$ Primary care physicians and rheumatologists referred patients with early arthritis to hospitals participating in the ESPOIR cohort project. Patients were eligible for inclusion if they were $18-70$ years of age and had either a definitive or a probable clinical diagnosis of RA or polyarthritis not better explained by another cause. Additional inclusion criteria were swelling of two or more joints for 6 weeks to 6 months, with no history of glucocorticoid or DMARD use. However, glucocorticoid therapy in a mean dosage $\leq 20 \mathrm{mg} /$ day given for $\leq 2$ weeks and discontinued at least 2 weeks earlier was allowed.

\section{Study design}

At inclusion into the ESPOIR cohort, all patients underwent a standardised interview; a general physical examination; laboratory tests including a CBC; viral serological tests (parvovirus B19, hepatitis B and C viruses, and HIV); immunological tests (ELISAs for IgM, IgG and IgA rheumatoid factors, and tests for anticitrullinated peptide antibodies and antinuclear antibodies); HLA DR phenotype determination; a cytokine profile (interleukin-1 receptor (IL-1R) $\alpha$, IL-6, IL-10, monocyte chemoattractant protein 1 (MCP-1), IL-4, IL-17, interferon (IFN) $\gamma$, tumour necrosis factor (TNF) $\alpha$, IL-16 and IL-2); urine tests; and radiographs of the chest, pelvis, hands and feet in the posteroanterior view, and feet in the oblique view. ${ }^{19}$ Each patient was evaluated by an ESPOIR study rheumatologist every 6 months for 2 years, then once a year for at least 10 years. Monitoring was stopped if a diagnosis other than RA was established. The rheumatologists used 0-100 visual analogue scales (VAS) to rate the certainty with which they diagnosed RA and established the absence of a better alternative diagnosis. All evaluations were free of charge.

A set of radiographs was obtained for each patient at baseline, then every 6 months at each rheumatologist visit. The set included posteroanterior views of the hands, wrists and feet, as well as oblique views of the feet. They were sent to the coordinating centre for independent interpretation by a rheumatologist (GJT) who had no information about the patients. For each radiograph, the reader followed a standardised procedure to assess the number of erosions according to the van der Heijde-modified Sharp system for posteroanterior views of the hands and feet. We computed the rate of erosion progression over the first year (difference between scores at 12 months and at baseline) and over the next 2 years (difference between scores at 36 and 12 months). ${ }^{20}$

Baseline eosinophilia was defined as a count $\geq 500$ / $\mathrm{mm}^{3}$. We determined the prevalence of eosinophilia at baseline and after 3 years, as well as the proportion of patients with persistent eosinophilia. We compared clinical, biological and immunological features in patients with and without eosinophilia at baseline and after 3 years. We also compared the two groups in terms of baseline radiographic structural damage and rates of structural damage progression during the first year and the next 2 years. In patients with eosinophilia, we determined the cause of eosinophilia, comorbidities, final diagnoses, and occurrence of extra-articular manifestations including vasculitis and treatments.

\section{Statistical analysis}

Data were described in the groups with and without eosinophilia at baseline, after 3 years, and at both time points. To identify factors associated with eosinophilia at baseline, we used SPSS V.21.0 software (SPSS, Chicago, Illinois, USA). Spearman's correlation was used for correlation between eosinophilia and other parameters. The $\chi^{2}$ test or Fisher's exact test, as appropriate, and the 
Mann-Whitney test were used for a univariate analysis of criteria collected at baseline and after 3 years. We included tests associated with prognosis in a multiple logistic regression with backward selection using the likelihood ratio test. $p$ Values $\leq 0.05$ were considered statistically significant.

\section{RESULTS}

Proportion, characteristics and final diagnoses of patients with baseline eosinophilia

Of the 813 patients in the cohort, 804 had interpretable data. Among them, 26 (3.2\%) had eosinophilia at baseline. Twenty-five of the 26 patients with eosinophilia according to the count $\left(\geq 500 / \mathrm{mm}^{3}\right)$ had a percentage higher or equal to $5 \%$. Their eosinophil counts ranged from 520 to $920 / \mathrm{mm}^{3}$, with a mean of $637.7 \pm 107.0$ / $\mathrm{mm}^{3}$. Ten of the 26 patients had a count between 500 and 599. In $6(23.1 \%)$ of the 26 patients, the eosinophilia was ascribed to atopic syndrome. No patients had evidence of helminth infection or tumour at baseline, but specific test were not carried out to exclude these diseases. The final diagnoses were RA in 19 patients, spondyloarthritis in 4 patients, unclassified arthritis in 1 patient, gout in 1 patient and osteoarthritis in 1 patient. After 3 years, 8 of 608 (1.3\%) patients had eosinophilia; only two of these eight patients also had eosinophilia at baseline.

There was no evidence that baseline eosinophilia predicted the subsequent development of extra-articular manifestations. Of the 17 patients with baseline eosinophilia and information on systemic manifestations 3 years later, none had cardiac, cutaneous, neurological, pulmonary or renal manifestations; and none had rheumatoid nodules. Among them, 5 (29.4\%) had xerostomia, compared to 92 of $512(18 \%)$ patients without baseline eosinophilia $(\mathrm{p}=0.16)$. Xerophthalmia was a feature after 3 years in one patient with baseline eosinophilia.

Comparison of baseline clinical, biological and immunological features in patients with and without baseline eosinophilia

Baseline eosinophilia was associated with higher leucocyte and lymphocyte counts $(\mathrm{p}=0.007$ and 0.02 , respectively). None of the other baseline characteristics listed in table 1 differed significantly between the two groups. IL-17 at baseline was significantly higher in the group with eosinophilia ( 0.78 vs $0.37 \mathrm{IU} / \mathrm{L}, \mathrm{p}=0.02)$. Most of the other cytokines listed in table 2 were higher in the group with baseline eosinophilia, but the differences were not statistically significant.

Comparison of clinical, biological and immunological

features after 3 years in patients with and without baseline eosinophilia

Baseline eosinophilia was associated with higher values for patient-assessed VAS disease activity (43.6 vs 28.4, $\mathrm{p}=0.05)$, morning stiffness intensity $(36.0$ vs 21.7, $\mathrm{p}=0.05)$ and health assessment questionnaire (HAQ) score $(0.9$ vs $0.5, \mathrm{p}=0.004)$, after 3 years (table 3 ). The difference between the two groups remained significant in the subpopulation of patients aged over 50 years (HAQ 1.1 vs $0.57, \mathrm{p}=0.02$ in patients with and without eosinophilia, respectively), suggesting that the overall results were not influenced by the normal increase of HAQ with age. There was no correlation between eosinophilia and disease activity, suggesting that presence or absence of eosinophilia is more important than the level of eosinophilia, to predict the outcome. Physician-assessed VAS disease activity scores and Disease Activity Score (DAS) 28 values were similar in the groups with and without eosinophilia $(\mathrm{p}=0.32$ and 0.15 , respectively).

A higher proportion of patients with baseline eosinophilia were taking DMARD therapy after 3 years, compared to the other patients $(94.7 \%$ vs $71.1 \%, \mathrm{p}=0.02)$. However, there were no significant differences between the two groups for the proportions of patients taking Methotrexate, glucocorticoids or biological therapy after 3 years. The number of patients was too small for analysis by subgroups. Methotrexate mean dosage was similar in both groups.

Using a logistic regression, we analysed baseline parameters associated with $\mathrm{HAQ}$ higher than 1 at 3 years. Among the baseline parameters classically associated to prognosis (C reactive protein, DAS28, IgM rheumatoid factor, anticitrullinated protein antibody, HAQ) and eosinophilia higher or equal to 500 , only $\mathrm{HAQ}$ remained in the model. Nevertheless, after deletion of HAQ both DAS28 $(\mathrm{OR}=1.4, \mathrm{p}<0.001)$ and eosinophilia $(\mathrm{OR}=3$, $\mathrm{p}=0.028$ ) remained in the model.

Comparison of radiographic structural damage in patients with and without baseline eosinophilia

Baseline radiographic changes were found in similar proportions of patients in the groups with and without baseline eosinophilia $(15.4 \%$ vs $13.4 \%, \mathrm{p}=0.77$ ) (table 1 ). Rates of progression of erosion over the first year and the next 2 years were similar in the two groups $(p=0.83$ and 0.41 , respectively; table 3 ).

\section{DISCUSSION}

The prevalence of baseline eosinophilia in patients with recent onset arthritis in France was only 3.2\%. Of the 26 patients with baseline eosinophilia, only 6 had another identified cause, which was atopic syndrome in every case. Thus, the eosinophilia seemed ascribable to the joint disease in most cases. According to the debateable value of the diagnosis of atopy, we evaluated patients as a single group. After 3 years, the prevalence of eosinophilia had dropped to $1.3 \%$, suggesting a response to specific therapy. Baseline eosinophilia did not predict the subsequent development of extra-articular manifestations. There was evidence that baseline eosinophilia 
Table 1 Comparison of baseline characteristics in the groups with and without baseline eosinophilia

\begin{tabular}{|c|c|c|c|}
\hline Features & $\begin{array}{l}\text { Eosinophils } \geq 500 / \mathrm{mm}^{3} \\
\mathrm{~N}=26\end{array}$ & $\begin{array}{l}\text { Eosinophils }<500 / \mathrm{mm}^{3} \\
\mathrm{~N}=778\end{array}$ & p Value \\
\hline Age, mean (SD) & $45.7(14.4)$ & $47.6(12.5)$ & 0.64 \\
\hline Females, n (\%) & 20/26 (76.9) & $598 / 778(76.9)$ & 1 \\
\hline DAS28, mean (SD) & $5.2(0.8)$ & $5.1(1.3)$ & 0.75 \\
\hline Patient-assessed VAS disease & $69.0(23.5)$ & $59.5(24.6)$ & 0.1 \\
\hline Morning stiffness & 99.8 (276.9) & $92.8(182.7)$ & 0.2 \\
\hline $\mathrm{HAQ}$ & $1.1(0.6)$ & $1.0(0.7)$ & 0.1 \\
\hline Rheumatoid nodules, n (\%) & $1 / 26(3.8)$ & 15/777 (1.9) & 0.41 \\
\hline Radiographic changes, $\mathrm{n}(\%)$ & $4 / 26(15.4)$ & $105 / 777(13.5)$ & 0.77 \\
\hline NSAID use, $\mathrm{n}(\%)$ & $14 / 25(56)$ & $358 / 699(51.21)$ & 0.64 \\
\hline Haemoglobin ( $g / d L)$, mean (SD) & $12.7(1.4)$ & $12.6(1.7)$ & 0.74 \\
\hline Platelets $/ \mathrm{mm}^{3}$, mean (SD) & $3.1 \times 10^{5}\left(0.7 \times 10^{5}\right)$ & $3.1 \times 10^{5}\left(1.0 \times 10^{5}\right)$ & 0.44 \\
\hline Leucocytes $/ \mathrm{mm}^{3}$, mean (SD) & $8.6 \times 10^{3}\left(2.2 \times 10^{3}\right)$ & $7.5 \times 10^{3}\left(2.7 \times 10^{3}\right)$ & 0.007 \\
\hline Lymphocytes $/ \mathrm{mm}^{3}$, mean (SD) & $2.1 \times 10^{3}\left(0.7 \times 10^{3}\right)$ & $1.8 \times 10^{3}\left(1.7 \times 10^{3}\right)$ & 0.02 \\
\hline Neutrophils $/ \mathrm{mm}^{3}$, mean (SD) & $5.3 \times 10^{3}\left(1.8 \times 10^{3}\right)$ & $4.9 \times 10^{3}\left(2.0 \times 10^{3}\right)$ & 0.20 \\
\hline CRP (mg/L), mean (SD) & $20.5(28.2)$ & $20.2(32.6)$ & 0.93 \\
\hline Creatinine $(\mu \mathrm{mol} / \mathrm{L})$, mean (SD) & $71.2(13.9)$ & $73.4(15.3)$ & 0.36 \\
\hline Positive RF, n (\%) & 9/26 (34.6) & $329 / 775(42.4)$ & 0.43 \\
\hline ACPA > 3N, n (\%) & $10 / 26(38.5)$ & $316 / 777$ (40.7) & 0.82 \\
\hline
\end{tabular}

Bold typeface indicates $p \leq 0.05$.

ACPA, anticitrullinated protein antibody; CRP, C reactive protein; DAS, Disease Activity Score; HAQ, health assessment questionnaire;

NSAID, non-steroidal anti-inflammatory drug; RF, rheumatoid factor; VAS, visual analogue scale.

predicted greater disease severity, with higher patientassessed VAS disease activity and morning stiffness scores, higher HAQ scores and greater use of DMARD therapy after 3 years.

We are not aware of previous studies specifically designed to assess eosinophilia in patients with recent-onset arthritis. Of 1000 unselected outpatients seen at a rheumatology clinic, $7.7 \%$ had eosinophilia, but the broad range of diagnoses, which included longstanding rheumatic diseases and venous thromboembolism, makes this finding difficult to interpret. ${ }^{17}$ Of 109 patients with recent or established RA in Argentina, 8 (7.3\%) had eosinophilia, which was consistently ascribed to parasitic infections. ${ }^{16}$ The discrepancy between these results and ours is related to the high prevalence of helminth infections in South America and to the long duration of RA in the earlier study (mean, 10.8 \pm 7.6 years).$^{21}$

In our patients with recent-onset arthritis, eosinophilia was consistently mild and often resolved with appropriate treatment. In all 26 patients with eosinophilia, the counts were lower than $1000 / \mathrm{mm}^{3}$. Moderate to severe eosinophilia in patients with recent-onset arthritis should prompt a thorough work up including morphological examination of a blood smear, urinalysis and serial stool examinations for ova and parasites, as recommended in other situations. ${ }^{1}$

Most of the baseline features showed no significant differences between the groups with and without baseline eosinophilia. However, lymphocyte counts were

Table 2 Comparison of baseline cytokine levels in the groups with and without baseline eosinophilia

\begin{tabular}{|c|c|c|c|}
\hline Cytokine & $\begin{array}{l}\text { Eosinophils } \geq 500 / \mathrm{mm}^{3} \\
\mathrm{~N}=26\end{array}$ & $\begin{array}{l}\text { Eosinophils }<500 / \mathrm{mm}^{3} \\
\mathrm{~N}=778\end{array}$ & p Value \\
\hline IL-1R $\alpha$, IU/L, mean (SD) & 1386.6 (801.9) & $1269.1(1065.8)$ & 0.17 \\
\hline IL-6, IU/L, mean (SD) & $24.7(17.7)$ & $23.8(43.1)$ & 0.06 \\
\hline IL-10, IU/L, mean (SD) & $2.9(13.8)$ & $0.6(10.8)$ & 0.63 \\
\hline MCP-1, IU/L, mean (SD) & $201.0(109.9)$ & $109.9(152.8)$ & 0.79 \\
\hline IL-4, IU/L, mean (SD) & $0.4(1.2)$ & $0.5(6.7)$ & 0.48 \\
\hline IL-17, IU/L, mean (SD) & $0.8(2.1)$ & $0.4(3.6)$ & 0.02 \\
\hline INF $\gamma$, IU/L, mean (SD) & $0.3(0.9)$ & $0.1(0.6)$ & 0.17 \\
\hline TNF $\alpha$, IU/L, mean (SD) & $3.12(3.4)$ & $2.6(5.6)$ & 0.38 \\
\hline $\mathrm{IL}-1 \beta, \mathrm{IU} / \mathrm{L}$, mean (SD) & $0.0(0.0)$ & $0.2(2.3)$ & 0.28 \\
\hline IL-2, IU/L, mean (SD) & $0.6(1.5)$ & $0.8(4.5)$ & 0.91 \\
\hline
\end{tabular}

Bold typeface indicates $\mathrm{p} \leq 0.05$.

IL, interleukin; IL-1R, interleukin-1 receptor; INF, interferon; MCP-1, monocyte chemoattractant protein 1; TNF, tumour necrosis factor. 
Table 3 Comparison of features after 3 years in the groups with and without baseline eosinophilia

\begin{tabular}{|c|c|c|c|}
\hline Features & $\begin{array}{l}\text { Eosinophils } \\
\geq 500 / \mathrm{mm}^{3} \\
\mathrm{~N}=26\end{array}$ & $\begin{array}{l}\text { Eosinophils } \\
<500 / \mathrm{mm}^{3} \\
\mathrm{~N}=778\end{array}$ & p Value \\
\hline DAS28, mean (SD) & $3.2(1.2)$ & $2.9(1.4)$ & 0.17 \\
\hline Patient VAS activity score, mean (SD) & $43.6(32.6)$ & $28.4(25.9)$ & 0.05 \\
\hline Physician VAS activity score, mean (SD) & $24.0(23.0)$ & $19.2(19.8)$ & 0.32 \\
\hline Morning stiffness intensity, mean (SD) & $36.0(29.7)$ & $21.7(23.3)$ & 0.05 \\
\hline $\mathrm{HAQ}$ score, mean (SD) & $0.9(0.7)$ & $0.5(0.6)$ & 0.004 \\
\hline CRP (mg/L), mean (SD) & $12.3(19.5)$ & $6.6(11.0)$ & 0.95 \\
\hline Rate of erosion progression during year 1 , mean (SD) & $3.6(4.0)$ & $3.0(4.6)$ & 0.83 \\
\hline $\begin{array}{l}\text { Rate of erosion progression between } \\
\text { year } 1 \text { and year } 3 \text {, mean (SD) }\end{array}$ & $2.5(3.2)$ & $2.6(4.2)$ & 0.41 \\
\hline Corticosteroids, n (\%) & 7/18 (38.9) & 229/606 (37.8) & 0.92 \\
\hline DMARD, n (\%) & $18 / 19(94.7)$ & $476 / 669$ (71.1) & 0.02 \\
\hline Methotrexate, n (\%) & $13 / 19(68.4)$ & $370 / 673(55.0)$ & 0.24 \\
\hline Methotrexate dosage (mg/week), mean (SD) & $14.6(3.5)$ & $13.3(3.9)$ & 0.22 \\
\hline Biological agent & $2 / 26(7.7 \%)$ & $89 / 778(11.4 \%)$ & 0.76 \\
\hline
\end{tabular}

higher in the group with baseline eosinophilia, suggesting lymphocyte hyperactivity accompanying the eosinophilia. Baseline IL-17 levels were also higher in the group with baseline eosinophilia, perhaps because this group had a higher proportion of patients with asthma. In vitro studies suggest that eosinophils may participate in the pathogenesis of allergic airway inflammation in asthma, increasing the production of IL-17 by CD4+ T cells. $^{22} 23$

Baseline eosinophilia did not predict the development of extra-articular manifestations, including vasculitis, within the next 3 years. Patients with baseline eosinophilia did not experience greater progression of structural damage compared to the other patients. These data are at variance with studies on the significance of eosinophilia in RA. ${ }^{12-15}$ However, these studies were conducted in the 1970s and 1980s, when the diagnosis of RA was usually delayed, and the available treatment options were limited. ESPOIR cohort patients underwent regular clinical, laboratory and radiographic monitoring starting within 6 months of onset of arthritis, which ensured the early diagnosis of cases of RA. In addition, they had access to new treatments that are effective against both the clinical symptoms and the radiographic damage. Thus, the absence of an association between baseline eosinophilia and extra-articular manifestations or worse structural damage may be related to the early use of effective drugs. Nevertheless, we found some evidence that baseline eosinophilia was associated with greater disease severity, as assessed after 3 years. Thus, patients with baseline eosinophilia gave higher selfassessed VAS disease activity and morning stiffness scores, and had greater functional impairment, as evaluated using the HAQ score. Importantly, a higher proportion of patients with than without baseline eosinophilia were taking DMARD therapy after 3 years.
Our study has several limitations. First, no standardised work up was performed to assess eosinophilia at baseline or after 3 years. We may therefore have overestimated the proportion of cases of eosinophilia due to the inflammatory joint disease. Second, among patients with eosinophilia, we did not separate those with and without atopic syndrome. In patients with atopic syndrome, we could not be certain that the eosinophilia was related to IgE-dependent hypersensitivity rather than to the inflammatory joint disease. Excluding these patients from the analysis might have produced different results.

\section{CONCLUSION}

Eosinophilia was rare in patients in France who had recent-onset arthritis in at least two joints, suggesting RA. Only about one-fourth of the patients with eosinophilia had another diagnosis known to cause this abnormality. Eosinophilia was mild and transient in most patients. Our data suggest that patients with mild baseline eosinophilia might respond to the treatment to a worse degree than those without, as they had higher patient-assessed disease activity, morning stiffness intensity, HAQ scores and DMARD use after 3 years.

\section{Author affiliations}

${ }^{1}$ Department of Rheumatology, CHU de la Cavale Blanche, Boulevard Tanguy Prigent, Brest, France

${ }^{2}$ EA 2216, INSERM ESPRI, ERI29 Université Bretagne Occidentale, Brest, France

${ }^{3}$ Department of Internal Medicine, Division of Rheumatology, Fundación Valle del Lili, ICESI University School of Medicine, Cali, Columbia

${ }^{4}$ Simone Veil Department of Health Sciences, Inserm U1173, University Versailles-Saint-Quentin, Montigny-Le-Bretonneux, Ile de France, France ${ }^{5}$ Rhumatologie \& Inserm, U905 (IRIB) CIC 1404, CHU Hôpitaux de Rouen, Rouen, France

Twitter Follow Alain Saraux at @alain.saraux 
Acknowledgements The authors thank Nathalie Rincheval, who was in charge of study monitoring and data management; as well as the investigators who recruited and followed the patients (F Berenbaum, Paris-Saint Antoine; MC Boissier, Paris-Bobigny; A Cantagrel, Toulouse; B Combe, Montpellier; M Dougados, Paris-Cochin; P Fardelone and P Boumier, Amiens; B Fautrel and P Bourgeois, Paris-La Pitié; RM Flipo, Lille; Ph Goupille, Tours; F Liote, Paris-Lariboisière; X Le Loet and 0 Vittecoq, Rouen; Mariette, Paris Bicêtre; 0 Meyer, Paris Bichat; Th Schaeverbeke, Bordeaux; and J Sibilia, Strasbourg).

Funding An unrestricted grant from Merck Sharp and Dohme (MSD) supported the first 5 years of the ESPOIR cohort study. The biological database was supported in part by two grants from the INSERM. The French Society for Rheumatology, Pfizer, Abbvie and Roche-Chugai also supported the ESPOIR cohort study.

Competing interests None declared.

Patient consent Obtained

Ethics approval Montpellier Ethic Board (France).

Provenance and peer review Not commissioned; externally peer reviewed.

Data sharing statement All data about the ESPOIR cohort are available on the website LaCohorteEspoir.fr.

Open Access This is an Open Access article distributed in accordance with the Creative Commons Attribution Non Commercial (CC BY-NC 4.0) license, which permits others to distribute, remix, adapt, build upon this work noncommercially, and license their derivative works on different terms, provided the original work is properly cited and the use is non-commercial. See: http:// creativecommons.org/licenses/by-nc/4.0/

\section{REFERENCES}

1. Rothenberg ME. Eosinophilia. N Engl J Med 1998;338:1592-600.

2. Roufosse FE, Goldman M, Cogan E. Hypereosinophilic syndromes. Orphanet J Rare Dis 2007:2:37.

3. Weller PF, Bubley GJ. The idiopathic hypereosinophilic syndrome. Blood 1994;83:2759-79.

4. Don IJ, Khettry U, Canoso JJ. Progressive systemic sclerosis with eosinophilia and a fulminating course. Am J Med 1978;65: 346-8.

5. Falanga V, Medsger TA. Frequency, levels, and significance of blood eosinophilia in systemic sclerosis, localized scleroderma, and eosinophilic fasciitis. J Am Acad Dermatol 1987;17:648-56.

6. Giordano M, Ara M, Valentini G, et al. Presence of eosinophilia in progressive systemic sclerosis and localized scleroderma. Arch Dermatol Res 1981;271:411-17.
7. Zittoun R, Debain P, James JM, et al. [Hematological manifestations and complications in Sjögren's syndrome (author's transl)]. Sem Hôp Organe Fondé Par Assoc Enseign Méd Hôp Paris 1978;54:1011-20.

8. Edelman J, Davis P, Owen ET. Prevalence of eosinophilia during gold therapy for rheumatoid arthritis. $J$ Rheumatol 1983;10:121-3.

9. Savolainen HA, Leirisalo-Repo M. Eosinophilia as a side-effect of methotrexate in patients with chronic arthritis. Clin Rheumatol 2001;20:432-4.

10. Schneider HA, Yonker RA, Katz P, et al. Rheumatoid vasculitis: experience with 13 patients and review of the literature. Semin Arthritis Rheum 1985;14:280-6.

11. Smith $\mathrm{DH}, \mathrm{Scott} \mathrm{DL}$, Zaphiropoulos GC. Eosinophilia in D-penicillamine therapy. Ann Rheum Dis 1983;42:408-10.

12. Winchester RJ, Koffler D, Litwin SD, et al. Observations on the eosinophilia of certain patients with rheumatoid arthritis. Arthritis Rheum 1971;14:650-65.

13. Panush RS, Franco AE, Schur PH. Rheumatoid arthritis associated with eosinophilia. Ann Intern Med 1971;75:199-203.

14. Sylvester RA, Pinals RS. Eosinophilia in rheumatoid arthritis. Ann Allergy 1970;28:565-8.

15. Dawes PT, Smith DH, Scott DL. Massive eosinophilia in rheumatoid arthritis: report of four cases. Clin Rheumatol 1986;5:62-5.

16. Chiardola F, Schneeberger EE, Citera G, et al. Prevalence and clinical significance of eosinophilia in patients with rheumatoid arthritis in Argentina. J Clin Rheumatol 2008;14:211-13.

17. Kargilı A, Bavbek N, Kaya A, et al. Eosinophilia in rheumatologic diseases: a prospective study of 1000 cases. Rheumatol Int 2004;24:321-4.

18. Combe B, Benessiano J, Berenbaum F, et al. The ESPOIR cohort: a ten-year follow-up of early arthritis in France: methodology and baseline characteristics of the 813 included patients. Joint Bone Spine 2007;74:440-5.

19. Devauchelle-Pensec V, Josseaume T, Samjee I, et al. Ability of oblique foot radiographs to detect erosions in early arthritis: results in the ESPOIR cohort. Arthritis Rheum 2008;59:1729-34.

20. Tobón G, Saraux A, Lukas C, et al. First-year radiographic progression as a predictor of further progression in early arthritis: results of a large national French cohort. Arthritis Care Res 2013;65:1907-15

21. Ponce OJ, Tapia-Tapia JC, Malaga G. Soil-transmitted helminth infections in South America. Lancet Infect Dis 2014;14:184.

22. Dias PM, Banerjee $\mathrm{G}$. The role of Th17/IL-17 on eosinophilic inflammation. J Autoimmun 2013;40:9-20.

23. Esnault S, Kelly EA, Nettenstrom LM, et al. Human eosinophils release IL-1 $\beta$ and increase expression of IL-17A in activated CD4+ T lymphocytes. Clin Exp All 2012;42:1756-64. 